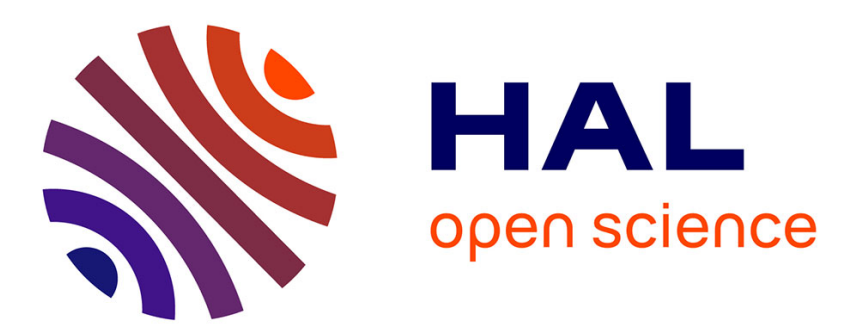

\title{
A benchmarking of machine learning techniques for solar radiation forecasting in an insular context
}

Philippe Lauret, Cyril Voyant, Ted Soubdhan, Mathieu David, Philippe Poggi

\section{To cite this version:}

Philippe Lauret, Cyril Voyant, Ted Soubdhan, Mathieu David, Philippe Poggi. A benchmarking of machine learning techniques for solar radiation forecasting in an insular context. Solar Energy, 2015, 112, pp.446 - 457. 10.1016/j.solener.2014.12.014 . hal-01101564

\section{HAL Id: hal-01101564 https://hal.science/hal-01101564}

Submitted on 9 Jan 2015

HAL is a multi-disciplinary open access archive for the deposit and dissemination of scientific research documents, whether they are published or not. The documents may come from teaching and research institutions in France or abroad, or from public or private research centers.
L'archive ouverte pluridisciplinaire HAL, est destinée au dépôt et à la diffusion de documents scientifiques de niveau recherche, publiés ou non, émanant des établissements d'enseignement et de recherche français ou étrangers, des laboratoires publics ou privés. 


\title{
A benchmarking of machine learning techniques for solar radiation forecasting in an insular context
}

\author{
Philippe Lauret ${ }^{1}$ \\ University of Reunion Island - PIMENT Laboratory \\ 15, Avenue René Cassin \\ BP 97715 Saint-Denis Cedex \\ philippe.lauret@univ-reunion.fr \\ Cyril Voyant \\ University of Corsica, CNRS UMR SPE 6134, 20250 Corte, France \\ cyrilvoyant@gmail.com \\ Ted Soubdhan \\ GRER, University of the Antilles and Guyana, \\ B.P. 592 UFR SEN - 97159 Pointe à Pitre, Guadeloupe \\ tsoubdha@univ-ag.fr \\ Mathieu David \\ University of Reunion Island - PIMENT Laboratory \\ 15, Avenue René Cassin \\ BP 97715 Saint-Denis Cedex \\ mathieu.david@univ-reunion.fr \\ Philippe Poggi \\ University of Corsica, CNRS UMR SPE 6134, 20250 Corte, France \\ philippe.poggi@univ-corse.fr
}

\begin{abstract}
In this paper, we propose a benchmarking of supervised machine learning techniques (neural networks, Gaussian processes and support vector machines) in order to forecast the Global Horizontal solar Irradiance (GHI). We also include in this benchmark a simple linear autoregressive (AR) model as well as two naive models based on persistence of the GHI and persistence of the clear sky index (denoted herein scaled persistence model). The models are calibrated and validated with data from three French islands: Corsica $\left(41.91^{\circ} \mathrm{N} ; 8.73^{\circ} \mathrm{E}\right)$, Guadeloupe $\left(16.26^{\circ} \mathrm{N} ; 61.51^{\circ} \mathrm{W}\right)$ and Reunion $\left(21.34^{\circ} \mathrm{S} ; 55.49^{\circ} \mathrm{E}\right)$. The main findings of this work are, that for hour ahead solar forecasting, the machine learning techniques slightly improve the performances exhibited by the linear $\mathrm{AR}$ and the scaled persistence model. However, the improvement appears to be more pronounced in case of unstable sky conditions. These nonlinear techniques start to outperform their simple counterparts for forecasting horizons greater than one hour.
\end{abstract}

\section{Keywords}

Intraday solar forecasting; machine learning techniques; statistical models

\footnotetext{
${ }^{1}$ Corresponding author. Tel.: +262 6926748 07; fax: +262 262938665 .

E-mail address: philippe.lauret@ univ-reunion.fr
} 


\section{Introduction}

Solar radiation forecasting is of great importance for an efficient integration of large shares of solar energy into the electricity grid. More precisely, in order to increase the integration of solar energy into electricity grids, accurate forecasts at various horizons are needed (Lorenz and Heinemann, 2012). This statement is reinforced in the case of insular grids (Diagne et al., 2014 ; Haurant et al., 2009; Voyant et al., 2009). Indeed, the intermittent character of solar energy together with the fact that the island's electricity grid is not connected, may endanger the stability of the grid and consequently the supply-demand balance. Solar forecasting may be very challenging in an insular context such as islands (like Reunion and Guadeloupe islands for instance) which usually experience a high spatial and temporal variability of the solar resource (Badosa et al., 2013; Calif et al., 2013; Praene et al., 2012). Due to this high variability, the insular grids can experience a drop of around $40-50 \%$ of the PV power output in minutes.

As a consequence, since the end of 2010 , the French government has limited by law the total power produced by the instantaneous integration of intermittent renewables (PV and wind) into the insular grids, to $30 \%$.

Since 2011, this limit has been reached for Reunion Island and Corsica. In order to assure reliable grid operation and to balance the supply and demand of energy, utilities require accurate forecasts at different granularities and for different forecast horizons. For instance, short term forecasts are needed for operational planning, switching sources or re-scheduling of means of production, programming backup, planning for reserve usage, and peak load matching (Kostylev and Pavloski, 2011). Depending on the forecast horizon, different input data and forecasting models are appropriate. Statistical models with on-site measured irradiance are adequate for the very short-term time scale ranging from 5 minutes up to 6 hours (Lorenz and Heinemann, 2012). Forecasts based on cloud motion vectors from satellite images (Lorenz and Heinemann, 2012) show a good performance for a temporal range of 30 minutes to 6 hours. For forecast horizons from about 6 hours onwards, forecasts based on Numerical Weather Prediction (NWP) models are generally more accurate (Inness and Dorling, 2012; Maini and Agrawal, 2006; Muselli et al., 1998).

In this work, we assess the performance of different models for intraday solar forecasting with a special focus on the hour ahead solar forecast, as it is the most-common operational forecast requested by the French utility company when operating the insular grids. Consequently, in this work, light is shed on the use of statistical models. Indeed, the solar radiation sequence can be seen as a time series, and therefore one can build statistical models to capture the underlying random processes and predict the next values. Several statistical techniques can 
be employed to forecast solar radiation time series. The spectrum of methods can range, for instance, from linear models like the autoregressive (AR) model to nonlinear models like artificial Neural Networks (NNs) or Support Vector Machines (SVMs). Many papers report the successful application of NNs in the field of solar forecasting (Inman et al., 2013; Mellit et al., 2009; Paoli et al., 2010; Voyant et al., 2013). Indeed, the availability of historical data on meteorological utility databases and the fact that NNs are data driven approaches, capable of performing non-linear mapping between sets of input and output variables, make this modelling tool very attractive. However, the use of machine learning techniques like the Support Vector Machine is relatively new (Zeng and Qiao, 2013; Fonseca Junior et al., 2013; Wolff et al., 2013) and techniques like Gaussian Processes (GPs) have been applied for instance to stream flow forecasting (Sun et al., 2014) but, to our best knowledge, have never been applied in the realm of solar forecasting. As mentioned above, the solar radiation sequence can be seen as a time series and in this survey we only make use of historical data in order to build the statistical models. In other words, no exogenous data are used to possibly improve the performance of the models. Some works reported a clear improvement of NNs models by adding exogenous data issued mainly from NWP models (Marquez and Coimbra, 2011; Voyant et al., 2012). However, in this work, it must be stressed that we deliberately discarded this possibility, as our primary intention here is to evaluate the performance of different machine learning techniques through a simple numerical set-up (i.e. only past GHI values are taken into account in the modelling process).

The performances of these techniques will be compared against a simple linear model and two naive persistence models. As a special emphasis is put on the case of insular grids, GHI data from three French overseas islands will serve to build and test the different models.

The remainder of this paper is organised as follows. Section 2 discusses the datasets used to calibrate the models and to assess the models' performance. Section 3 describes the clear sky model used to detrend the solar irradiance time series from its deterministic components. Section 4 defines the numerical experiments set-up while section 5 briefly introduces the machine learning techniques and depicts the structure of the different models. Section 6 presents the results of the benchmark. Finally, Section 7 gives some concluding remarks.

\section{Context of study and datasets}

Most of the techniques studied in this work are statistical learning methods that require past measured GHI values in order to build the different models. 
Further, the machine learning techniques investigated in this work are supervised learning methods, which consist in learning input-output mappings from empirical data (the training dataset). Consequently, in order to build and to validate the different models, data have been divided in to training and test datasets. As for all experimental acquisitions, missing values are observed for the three considered sites (less than $2 \%$ of the data), a classical cleaning approach was operated in order to identify and remove this data.

\subsection{Case of Reunion Island}

Reunion Island exhibits a particular meteorological context dominated by a large diversity of microclimates (David, 2005). Two main regimes of cloudiness are superposed: the clouds driven by synoptic conditions over the Indian Ocean and the orographic cloud layer generated by the local reliefs (Badosa et al., 2013). The data used to build the models are Global Horizontal Irradiances (GHI) measured at the meteorological station of Saint-Pierre $\left(21^{\circ} 34^{\prime} \mathrm{S} ; 55^{\circ} 49^{\prime} \mathrm{E}, 75 \mathrm{~m}\right.$ a.s.1) located in the southern part of Reunion Island. Measurements are available on an hourly basis and two years of data (2012 and 2013) are used respectively for the building and appraisal of the models. The station measures the GHI every six seconds and the 1-minute averages are recorded. The hourly used data correspond to the average of the previous 60 minutes of measurements. The solar irradiance is measured with a secondary standard pyranometer (CMP 11 from Kipp \& Zonen). The precision of the pyranometers is $\pm 3.0 \%$ for the daily sum of GHI. Measurement quality is an essential asset in any solar resource forecasting study. The site of Saint-Pierre is well maintained and has followed the radiometric techniques regarding calibration, maintenance and quality control. Each data point has been processed with SERI-QC quality control software (Maxwell et al., 1993).

\subsection{Case of Corsica}

The data used to build the models are GHI measured at the meteorological station of Ajaccio (Corsica, France, $41^{\circ} 91 \mathrm{~N}, 8^{\circ} 73 \mathrm{E}, 4 \mathrm{~m}$ asl). This station is equipped with pyranometers (CMP 11 from Kipp \& Zonen) and standard meteorological sensors (pressure, nebulosity, etc.). It is located near the Mediterranean Sea (100m) and nearby mountains $(1000 \mathrm{~m}$ altitude at $40 \mathrm{~km}$ from the site). This specific geographical configuration makes nebulosity difficult to forecast. The Mediterranean climate is characterized by hot summers with abundant sunshine and mild, dry and clear winters. The data representing the global horizontal solar radiation were measured on an hourly basis from 1998 to 1999 . The first year has been used to build our models and the last year to test them. 


\subsection{Case of Guadeloupe}

We used a two-year database (2012 and 2013) of GHI measured on an hourly basis at the meteorological station of Le Raizet (Météo France 16 $26 \mathrm{~N}, 61^{\circ} 51 \mathrm{~W}$; $11 \mathrm{~m}$ a.s.l) located in the middle of the island. This site is not free of influence from the sea and the mountains. The station is equipped with pyranometers (CM 22 from Kipp \& Zonen) and standard meteorological sensors (air temperature, wind speed and direction, nebulosity, etc.).

\subsection{Sites analysis}

This section aims at analysing the sky conditions experienced by each site. Table 1 lists the sites' characteristics and also gives (last line) a metric that characterizes the solar variability of the site. This metric proposed by (Hoff and Perez, 2012) is the standard deviation of the change in the clear sky index. A site with variability above 0.2 is considered as experiencing very unstable conditions (Hoff and Perez, 2012; David et al., 2013). As seen and contrary to sites of Corsica and Reunion, the variability of the site of Guadeloupe is above this threshold.

Fig. 1 plots the distribution of the clear sky index (computed with the Bird model) for each site. Again, one can see that the site of Guadeloupe exhibits more variable cloud situations. Conversely, the sites of Saint-Pierre and Ajaccio show more occurrences of clear skies (see Table 1).

\begin{tabular}{cccc}
\hline Site & $\begin{array}{c}\text { Saint-Pierre } \\
\text { (REUNION) }\end{array}$ & $\begin{array}{c}\text { Le Raizet } \\
\text { (GUADELOUPE) }\end{array}$ & $\begin{array}{c}\text { Ajaccio } \\
\text { (CORSICA) }\end{array}$ \\
\hline Period of record & $01 / 01 / / 2012$ & $01 / 01 / 2012$ & $01 / 01 / 1998$ \\
Longitude & $31 / 12 / 2013$ & $31 / 12 / 2013$ & $31 / 12 / 1999$ \\
Latitude & $55.491^{\circ} \mathrm{E}$ & $61.516^{\circ} \mathrm{W}$ & $8.733^{\circ} \mathrm{E}$ \\
Time zone (hours) & $21.34^{\circ} \mathrm{S}$ & $16.264^{\circ} \mathrm{N}$ & $41.917^{\circ} \mathrm{N}$ \\
Elevation (m) & +4 & -4 & +1 \\
Pressure (Pa) & 75 & 11 & 4 \\
Ozone (cm) & 0.2655 & 0.2447 & 0.3328 \\
Water vapor (cm) & 2.933 & 3.932 & 1.927 \\
AOD 500nm (cm) & 0,072 & 0,149 & 0.170 \\
AOD 380nm (cm) & 0.090 & 0.161 & 0,191 \\
Ba (Bird, 1981) & 0.84 & 0.84 & 0.84 \\
Nb. of clear sky hours & 2651 & 637 & 2641 \\
Bird clear sky model & $3.82 \%$ & $4.44 \%$ & $4.75 \%$ \\
accuracy (rRMSE) & & &
\end{tabular}




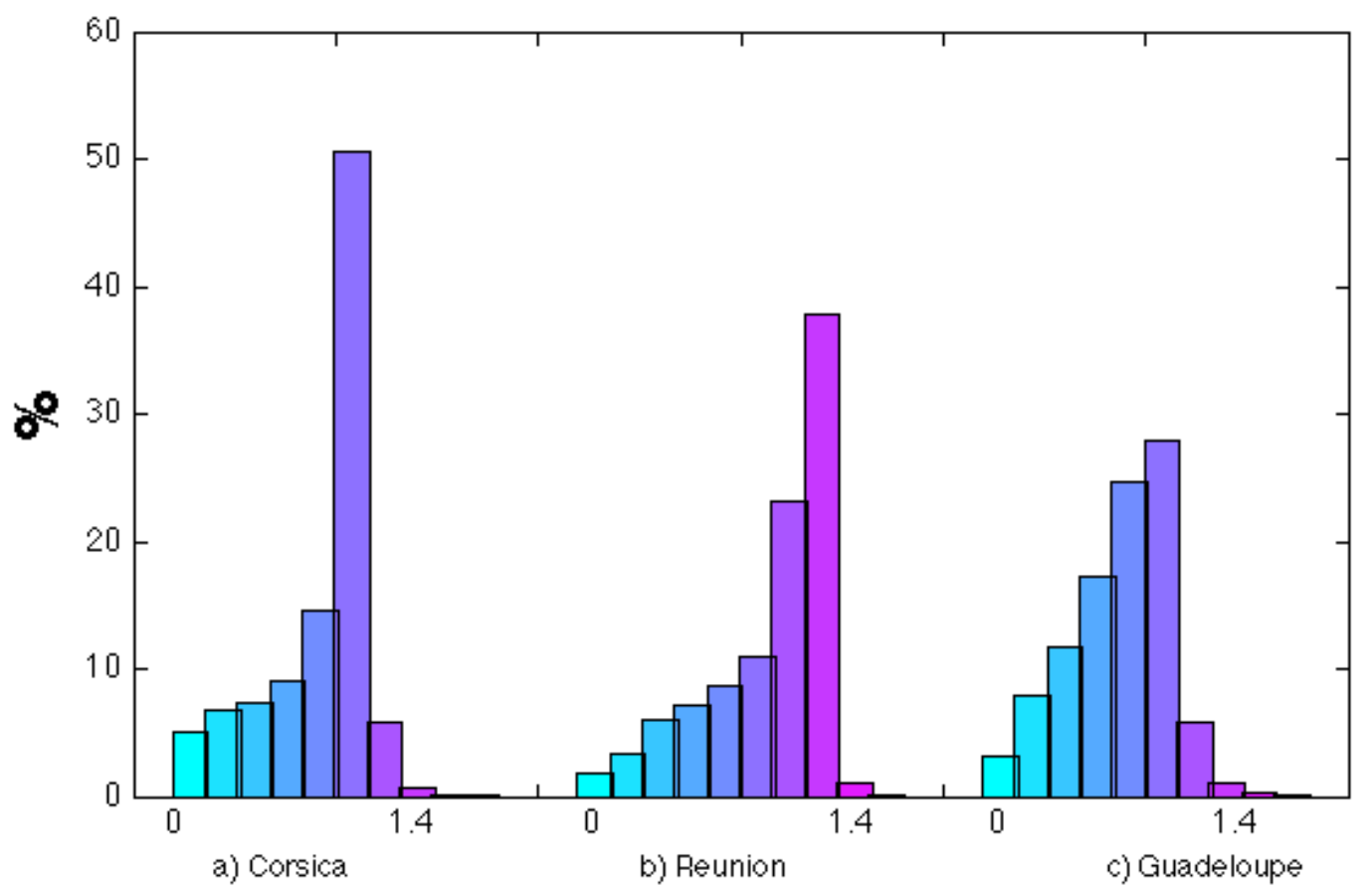

Figure 1. Clear sky index distribution for the three sites.

\section{Data pre-processing}

A key feature in the identification of linear models like AR models is the data transformation that is often needed to make the time series stationary. Stationarity means that the statistical characteristics of the time series such as the mean and the autocorrelation structure are constant over time (Chatfield, 2004). In this survey, as the original solar radiation series is not stationary (daily and annual seasonalities), we used clear sky models in an attempt to obtain a stationary hourly solar series. More precisely, we obtained a new deseasonalized series $\left\{k^{*}\right\}$, the so-called clear sky index series, by applying the following data transformation (Eq. (1)):

$k^{*}=I_{g} / I_{c l s k}$

where $I_{g}$ is the measured global irradiance and $I_{c l s k}$ is the output of the specific clear sky model. This transformation makes use of the fact that the global irradiance $I_{g}$ can be decomposed into a deterministic clear sky component and a stochastic cloud cover component. With this methodology, the models designed in this work are dedicated to the stochastic part of the global radiation, leaving the deterministic part to be modelled by 
the clear sky model. One may notice however that this transformation is not optimal (i.e. the time series of clear sky index may still exhibit some heteroscedasticity) and one has to apply some additional pre-processing techniques like differencing the clear sky index time series $\left\{k^{*}\right\}$ to remove the remaining trend and/or stabilize the variance. Another possibility is to make use of integrated ARMA (ARIMA) models (Chatfield, 2004) in order to treat non-stationary series or to apply the seasonal ARMA version (SARIMA) for seasonal time series. It must be noted that the same type of pre-processing will be applied to the machine learning methods assessed in this work. Indeed, in practice, it is usually admitted that data normalisation (as it is the case here) facilitates the learning process of these methods. In this work, the Bird clear sky model (Bird and Huldstrom, 1981) is used to pre-process the data of the three sites. This clear sky model will also permit the derivation of a naive model based on the persistence of the clear sky index as described in section 5.1.

\subsection{Bird model}

The Bird model (Bird and Huldstrom, 1981) is a well-known broadband model that generates clear sky irradiances with acceptable accuracy and with only few inputs (Badescu et al., 2013). For this study, the Aerosol Optical Depths (AODs) and the amount of the atmosphere components in a vertical column are set to their climatological means and they remain constant all along the years used in this work. These climatological averages were derived from the AERONET network (AERONET, 2013) for the AODs and the water vapor. The ozone atmospheric content is retrieved form the World Ozone Monitoring Mapping provided by the Canadian government (Ozone, 2014). The value of the parameters used for the three studied sites are given in Table 1.

The forecasting accuracy of the models proposed in this work depends on the accuracy of the clear sky method used to derive the clear sky index. In order to evaluate this error induced by the Bird model, only the clear sky periods are considered (Reno et al., 2012). The clear sky hours were detected using the Ineichen method (Ineichen, 2006) applied to the two years of measured hourly global irradiance. The two last lines of Table 1 give the number of clear sky hours detected and the relative Root Mean Square Error (rRMSE) of the corresponding clear sky irradiance produced by the Bird model. The performances of the Bird model are consistent with previous results and particularly in the case of La Reunion and Corsica (Cros et al. 2013).

\subsection{Filtering methodology}


Concerning the global radiation forecasting, it is a common practice to filter out the data in order to remove night hours and to objectively compare the studied predictors. This choice is justified because during these periods there is obviously no significant solar radiation to generate electricity (i.e. low potential overnight). We chose to apply a filtering criterion based on the solar zenith angle (SZA): solar radiation data for which the solar zenith angle is greater than $80^{\circ}$ have been removed. In addition, this filtering process allows to discard data with less precision as measurement uncertainties associated to pyranometers are typically much higher than $\pm 3.0 \%$ for SZA $>80^{\circ}$. Notice also that for the sunrise and sunset, the prediction is also very difficult (mainly for mountainous areas) owing to the geographic shield.

\section{Numerical experiments set-up}

The goal of this paper is to evaluate some machine learning techniques in order to predict next values of solar irradiance from only past values of the irradiance i.e. no exogenous variables are used. In other words, all forecasting methods described in this work seek to find a generic model $F$ of the form given by Eq. (2).

$\hat{k}^{*}(t+h)=F\left(k^{*}(t), k^{*}(t-1), \cdots, k^{*}(t-p)\right)$ for $h=1,2, \cdots, 6$

where the sign $\wedge$ is used to identify the forecast variable and the sequence $\left\{k^{*}(t), k^{*}(t-1), \cdots, k^{*}(t-p)\right\}$ represents the time series of $p$ past values of the clear sky index. The forecast horizon denoted by the letter $h$ usually ranges from 1 hour to 6 hours (intraday solar forecasting). In our case, as mentioned above, the variable of interest is the clear sky index $k^{*}$. Given forecasts of the clear sky index, GHI forecasts can be obtained by using Eq. (1). All the statistical methods described in this work are supervised learning methods or data-driven approaches. As a consequence, the techniques rely on the information content embedded in the training data in order to produce forecasts on unseen data. More precisely, the models' parameters are determined with the help of $n$ pairs of input and output examples contained in the training data. Once the model is fitted, the model can be evaluated on a test dataset. In our context, $\mathcal{D}=\left\{\mathbf{x}_{\mathrm{i}}, y_{i}\right\}_{\mathrm{i}=1}^{\mathrm{n}}$ represents the training dataset. The vector $\mathbf{x}_{\mathrm{i}}$ contains the $p$ past values of the clear sky index for training and $y_{i}$ refer to the corresponding value of the clear sky index for the horizon $h$ of interest. The column vector inputs for all $n$ training cases can be aggregated in the so-called $n \times p$ design matrix $\mathbf{X}$ and the corresponding model's outputs (or targets) are collected in the vector $\mathbf{y}$ so we can write $\mathcal{D}=\{\mathbf{X}, \mathbf{y}\}$. Similarly, considering $n_{*}$ test cases, we have $\mathcal{D}_{*}=\left\{\mathbf{X}_{*}, \mathbf{y}_{*}\right\}$ for the test dataset.

\section{Brief description of the prediction techniques}


In this section, we present the three different kind of prediction methodologies evaluated in this study: naive models, linear models and non-linear models.

\subsection{Naive models}

Two naive predictors are studied in this work. The first is the simple persistence model defined by Eq. (3).

$\hat{I}_{g}(t+h)=I_{g}(t)$

It simply states that future values of GHI are equal to GHI observed at time $t$ (i.e. the atmospheric conditions remain unchanged between current time $t$ and future time $t+h$ ). One way to improve this simple model is to take into account the course of the sun by using a clear sky model and to define persistence on the clear sky index i.e. $\widehat{k^{*}}(t+h)=k^{*}(t)$. The corresponding GHI forecast can be obtained through Eq. (4):

$\hat{I}_{g}(t+h)=I_{g}(t) \times I_{\operatorname{clsk}(t+h)} / I_{c l s k}(t)$

In the rest of the paper, this persistence on the clear sky index will be called scaled persistence (SC-pers) model.

\subsection{Linear model: autoregressive process}

In an AR model (Chatfield, 2004), the future value of a variable namely $\hat{k}^{*}(t+h)$ is assumed to be a linear combination of several past observations as shown by Eq. (5):

$\widehat{k^{*}}(t+h)=\phi_{0}+\sum_{i=0}^{p} \phi_{i+1} k^{*}(t-i)+\epsilon_{t}$

where $\epsilon_{t}$ is a white noise with variance $\sigma^{2}$. The model's parameters are the $\left\{\Phi_{i}\right\}_{i=0,1, \cdots p+1}$ and $p$ is called order (or autoregressive order) of the model. One key challenge in the building of AR models is to determine the appropriate model order. Methods based on the autocorrelation coefficients (ACF) and partial autocorrelation coefficients (PACF) analysis are proposed to select the best orders (Chatfield, 2004). However, these two techniques are based on linearity assumptions. In this study, the complexity of the model governed by the autoregressive order $p$ is determined with the auto mutual information factor (see section 5.7 for details).

\subsection{Neural network model}

A NN with $d$ inputs, $m$ hidden neurons and a single linear output unit defines a non-linear parameterized mapping from an input vector $\mathbf{x}$ to an output $y$ given by the relationship (see Eq. (6)):

$y(\mathbf{x} ; \mathbf{w})=\sum_{j=1}^{m} w_{j} f\left(\sum_{i=1}^{d} w_{j i} x_{i}+b_{1}\right)+b_{2}$

Each of the $m$ hidden units are related to the tangent hyperbolic function $f(x)=\left(e^{x}-e^{-x}\right) /\left(e^{x}+e^{-x}\right)$. The parameter vector $\mathbf{w}=\left(\left\{w_{j}\right\},\left\{w_{j i}\right\}, b_{1}, b_{2}\right)$, which contains a set of weights $\left\{w_{j}\right\},\left\{w_{j i}\right\}$ and two biases $b_{1}, b_{2}$, 
governs the non-linear mapping and is estimated during a phase called the training or learning phase. During this phase, the NN is trained using the dataset $\mathcal{D}$. The second phase, called the generalization phase, consists of evaluating on the test dataset $\mathcal{D}_{*}$, the ability of the $\mathrm{NN}$ to generalize, that is to say, to give correct outputs when it is confronted with examples that were not seen during the training phase.

For our application, the relationship between the output $\hat{k}^{*}(t+h)$ and the inputs $\left\{k^{*}(t), k^{*}(t-1), \cdots, k^{*}(t-\right.$ p)\} has the form given by Eq. (7):

$\hat{k}^{*}(t+h)=\sum_{j=1}^{m} w_{j} f\left(\sum_{i=0}^{p} w_{j i} k^{*}(t-i)+b_{1}\right)+b_{2}$

As shown by the preceding equation, the $\mathrm{NN}$ model is equivalent to a nonlinear autoregressive (AR) model for time series forecasting problems. In a similar manner as for the AR model, the number of past input values $p$ is calculated with the auto mutual information factor (see section 5.7 for details). In this work, and as described by Eqs. (6) and (7), we used only one hidden layer as it is proved theoretically that only layer is sufficient to approximate any continuous function ( Hornik et al, 1989). As a rule of thumb, our experience in building NNs (Voyant et al., 2013) led us to choose as many hidden units as NN inputs. Careful attention must be put on the building of the model, as a too complex NN will easily fit the noise in the training set instead of modelling the underlying physical process that generates the data. In other words, the model will exhibit a low training error but will offer a poor generalization performance. This problem is called overfitting in the machine learning community (Bishop, 1995). The NN complexity is in relation with the number of hidden units or conversely the dimension of the vector w. Several techniques like pruning (Lauret et al., 2006) or Bayesian regularization (MacKay, 1992) can be employed to control the NN complexity. In the present study, the NN model has been computed with the Matlab@ software and its Neural Network toolbox. The optimization process is based on the Levenberg-Marquardt learning algorithm with a max fail parameter set to 3. This procedure is, in fact, called early stopping in the NN community (Bishop, 1995) and make use of a validation set in order to control the NN complexity and therefore is a means to prevent overfitting. Note that a particular NN approach based on Bayesian inference (Lauret et al., 2008) was tested during the simulations. However, as no added value was brought out by the approach, we chose to not present this sophisticated methodology and the associated results.

\subsection{Gaussian Process model}

Gaussian Processes (GPs) are a relatively recent development in non-linear modelling (Rasmussen and Williams, 2006). GPs are generally stated as a kernel-based method. Indeed, it can be shown (Rasmussen and Williams, 
2006) that, given $n$ training samples, the prediction for an input test vector $\mathrm{x}_{*}$ can be seen in terms of a linear combination of $n$ kernel functions; each one centered on a training point. Therefore, the forecasted clear sky index is given by Eq. (8):

$\hat{k}^{*}(t+h)=\sum_{\mathrm{i}=1}^{\mathrm{n}} \alpha_{\mathrm{i}} k_{f}\left(\mathrm{x}_{\mathrm{i}}, \mathrm{x}_{*}\right)$

where $k_{f}$ denotes the squared exponential covariance function $k_{f}\left(x_{p}, x_{q}\right)=\sigma_{f}^{2} \exp \left[\frac{-\left(x_{p}-x_{q}\right)^{2}}{2 l^{2}}\right]$ and $\mathbf{x}_{\mathbf{i}}$ is the ith input training vector. $\sigma_{f}^{2}$ and $l$ are called hyperparameters of the covariance function. They control the model complexity and can be learned (or optimized) from the training data at hand (Rasmussen and Williams, 2006). More precisely, these hyperparameters are set through the maximization of a function called the marginal likelihood or evidence (Rasmussen and Williams, 2006). The coefficients $\alpha_{i}$ are obtained by a matrix multiplication between a covariance matrix (resulting from the application of the covariance function on all the training data points) and the vector of the $n$ training output samples $\mathbf{y}$. For all the details regarding the GP calculations, the interested reader is referred to (Rasmussen and Williams, 2006) or (Lauret et al., 2012).

\subsection{Support vector machine}

The support vector machine (SVM) is another kernel based machine learning technique used in classification tasks and regression problems (Vapnik, 1995). Support vector regression (SVR) is based on the application of support vector machines to regression problems (Smola and Schölkopf, 2004). This method has been successfully applied to time series forecasting tasks (Muller et al., 1997). In a similar manner as for the GPs, the prediction calculated by a SVR machine for an input test case $\mathrm{x}_{*}$ is given by Eq. (9):

$\hat{k}^{*}(t+h)=\sum_{i=1}^{n} \alpha_{i} k_{r b f}\left(\mathbf{x}_{i}, \mathbf{x}_{*}\right)+b$

$k_{r b f}$ denotes the radial basis covariance function $k_{r b f}\left(x_{p}, x_{q}\right)=\exp \left[-\gamma\left|\left(x_{p}-x_{q}\right)\right|\right]$ with hyperparameter $\gamma$ The parameter $\mathrm{b}$ (or bias parameter) is derived from the preceding equation and some specific conditions (see Smola and Schölkopf, 2004 for details).

In the case of SVR, the coefficients $\alpha_{i}$ are related to the difference of two Lagrange multipliers, which are the solutions of a quadratic programming (QP) problem (Smola and Schölkopf, 2004). Unlike NNs, which are confronted with the problem of local minimum, here the problem is strictly convex and the QP problem has a unique solution. In addition, it must be stressed (unlike GPs) that not all the training patterns participate to the preceding relationship. Indeed, a convenient choice of a cost function i.e. Vapnik's $\varepsilon$-insensitive function (Smola and Schölkopf, 2004) in the QP problem enables to obtain a sparse solution. The latter means that only 
some of the coefficients $\alpha_{i}$ will be nonzero. The examples that come with non-vanishing coefficients are called Support Vectors.

The parameters related to the SVM optimization process are a parameter $\mathrm{C}$ that control the trade-off between overfitting and generalization ability of the algorithm, a parameter $v$ that controls the amount of support vectors used in the regression and the parameter $\gamma$ of the covariance function that controls the smoothness of the covariance function (Fonseca Junior et al., 2013). These parameters have been optimized through the use of a kfold cross-validation procedure (Fonseca Junior et al., 2013).

In the present study, regarding the implementation of the support vector regression, we used the LibSVM library (Chang et al., 2011).

Like in the NN case, other kinds of support vector methodologies were tested e.g. the multi-class SVMs (Zeng et al.,2012; Yang et al., 2013; Czibula et al., 2012). The corresponding results were systematically worse than those from SVR. Thereby, we prefer to not describe these other methodogies in order to make the paper more readable.

\subsection{Some brief comments related to the optimization of the machine learning based models}

This section aims to highlight some points when one has to implement machine-learning techniques like NNs, SVMs or GPs. First, we would like to emphasize the automatic control of the model complexity brought by the SVM and GP methods. Let us recall that this control is a prerequisite for obtaining an optimized model that will not lead to overfitting. For these two methods, only a few parameters (also called hyperparemeters) control the model complexity. Further, the optimization of these control parameters can be done from the training data through the use of a principled framework (Rasmussen and Williams, 2006; Vapnik, 1995).

Conversely, NNs suffer from the lack of such principled framework. As a black-box approach, NNs are not so easy to apply in practice due to the many decisions, which needed to be made: what architecture, what learning rate, what regularization term etc. Generally, these knobs are set by rules of thumb, trial and error or the use of reserved data (validation set) to assess the generalization ability of the NN. In addition, for a particular NN, the search for a good set of weights for a given training set is more complicated because that there can be local optima in the optimization problem; this can cause significant difficulties in practice. Conversely, as mentioned above, SVMs and GPs are not plagued with the problem of local minima as NNs are. Actually, one has to be an expert in order to build a NN or one has to use sophisticated techniques like the Bayesian Regularization method (Lauret et al., 2008) in order to control the model complexity. 


\subsection{Determination of the number of lagged inputs}

One step common to all models is the number of endogenous inputs to consider. In this work, we used a novel technique based on the Mutual Information (MI) in order to determine the number of lagged inputs (Voyant et al., 2014). We chose to apply the same methodology for all numerical experiments by using the auto-information of the signal. This parameter measures the reduction of uncertainty in $k^{*}(t)$ after observing $k^{*}(t-i)(i=$ $0,1, \ldots, N ; N$ number of observations). So MI can measure non-monotonic and other more complicated relationships. It can be expressed as a combination of marginal and conditional entropies (respectively $H\left(k^{*}(t)\right.$ ) and $\left.H\left(k^{*}(t) \mid k^{*}(t-i)\right)\right)$ as described in Eq. (10):

$M I\left(k^{*}(t), k^{*}(t-i)\right)=H\left(k^{*}(t)\right)-H\left(k^{*}(t) \mid k^{*}(t-i)\right)$

This quantity should be understood as the amount of randomness of the random variable $k^{*}(t)$ given that you know the value of $k^{*}(t-i)$. For details regarding the MI formalism, the interested reader is referred to (Voyant et al., 2014). The maximum of lagged inputs to consider (i.e. number of inputs of the NN, SVM and GP) corresponds to the first minimum of the auto mutual information (Parviz et al., 2008). For example, if the first minimum corresponds to the 10th time lag, the NN will be constructed with 10 inputs.

\section{Results}

Several attempts have been made in order to define the state-of-the art validation metrics (Hoff et al., 2012; Coimbra et al., 2013; David et al., 2012). In the realm of the solar forecasting community, the commonly used error metrics are: the Root Mean Square Error (RMSE), Mean Absolute Error (MAE) and Mean Bias Error (MBE). The reader is referred to Appendix A for the definition of these error metrics. However, their relative counterparts (rRMSE, rMBE and rMAE) obtained by dividing the absolute error measures by the average of the daytime values of the GHI, are usually preferred as the utility industry desires to understand error in relative terms rather than absolute terms (Hoff et al., 2012). In this work, in order to characterize the quality of the forecasts, we provide the standard set of relative error metrics. We also include a new metric: the forecast skill

parameter $s$. The latter proposed by (Coimbra et al., 2013) is given by $s(\%)=\left(1-\frac{R M S E_{m e t h o d}}{R M S E_{S C}-\text { pers }}\right) \times 100$ where $R M S E_{\text {method }}$ stands for the RMSE of each forecasting method and $R M S E_{S C-\text { pers }}$ is the RMSE of the scaled persistence model. With this definition, the scaled persistence model has a forecast skill $s=0 \%$. A value of $s=100 \%$ denotes a perfect forecast $\left(R M S E_{\text {method }}=0 \mathrm{~W} \cdot \mathrm{m}^{-2}\right)$. Negative values of $s$ indicate that the forecasting 
model fails to outperform the scaled persistence model while positive values of $s$ means that the forecasting method improves on scaled persistence (Coimbra et al., 2013). Further, the higher the s-skill score, the better the improvement.

\subsection{Hour ahead GHI forecasts}

In this section, we present the results of the benchmarking study for the three insular sites (Corsica, Reunion and Guadeloupe). As previously mentioned in section 3, the Bird clear sky model is used to pre-process the original GHI time series of the three locations. The training of the models was operated with one year of data and the validation period (or test period) covers also one year. Table 2 lists the accuracy (on the one year validation period) of the different methods in the case of hour ahead forecasts. In addition to the annual performance of each model (annual rRMSE) and in order to exhibit an eventual seasonal dependency, Table 2 also reports their performance for each quarter of the year and Fig. 2 better highlights the annual performance of the different methods.

\begin{tabular}{|c|c|c|c|c|c|c|c|}
\hline \multirow[b]{2}{*}{ Locations } & \multirow[b]{2}{*}{ Types } & \multirow[b]{2}{*}{ Models } & \multirow[b]{2}{*}{$\begin{array}{c}\text { Annual } \\
\text { (rRMSE) }\end{array}$} & \multicolumn{4}{|c|}{ Quarters (rRMSE) } \\
\hline & & & & 1st & 2nd & 3rd & 4th \\
\hline \multirow{7}{*}{$\begin{array}{c}\text { Corsica } \\
\text { (Ajaccio) }\end{array}$} & \multirow{2}{*}{ Naive } & Pers & 31.94 & 36.53 & 30.14 & 27.13 & 36.69 \\
\hline & & SC-pers & 21.00 & 26.19 & 19.22 & 16.21 & 25.51 \\
\hline & \multirow{3}{*}{ Non-linear } & SVR & 19.92 & 24.78 & 18.55 & 15.39 & 23.64 \\
\hline & & $G P$ & 19.71 & 24.60 & 18.28 & 15.26 & 23.37 \\
\hline & & $N N$ & 19.65 & 24.43 & 18.25 & 15.15 & 23.47 \\
\hline & Linear & $A R$ & 20.43 & 25.08 & 18.88 & 15.81 & 24.96 \\
\hline & Gain in rRMSE & & $+1.35 \%$ & $+1.76 \%$ & $+0.97 \%$ & $+1.06 \%$ & $+2.14 \%$ \\
\hline \multirow{4}{*}{$\begin{array}{c}\text { Reunion } \\
\text { (Saint- } \\
\text { Pierre) }\end{array}$} & Naive & $\begin{array}{c}\text { Pers } \\
\text { SC-pers }\end{array}$ & $\begin{array}{l}34.21 \\
21.47\end{array}$ & $\begin{array}{l}36.23 \\
25.84\end{array}$ & $\begin{array}{l}35.32 \\
21.05\end{array}$ & $\begin{array}{l}30.28 \\
15.03\end{array}$ & $\begin{array}{l}34.78 \\
22.37\end{array}$ \\
\hline & Non-linear & $\begin{array}{c}\text { SVR } \\
G P \\
N N \\
\end{array}$ & $\begin{array}{l}21.22 \\
21.07 \\
21.14 \\
\end{array}$ & $\begin{array}{l}24.68 \\
24.56 \\
24.65 \\
\end{array}$ & $\begin{array}{l}20.03 \\
20.02 \\
19.85 \\
\end{array}$ & $\begin{array}{l}16.39 \\
15.79 \\
15.96 \\
\end{array}$ & $\begin{array}{l}22.50 \\
22.53 \\
22.65 \\
\end{array}$ \\
\hline & Linear & $A R$ & 21.36 & 25.23 & 20.40 & 15.20 & 22.94 \\
\hline & Gain in rRMSE & & $+0.4 \%$ & $+1.28 \%$ & $+1.2 \%$ & $-0.17 \%$ & $-0.13 \%$ \\
\hline \multirow{4}{*}{$\begin{array}{l}\text { Guadeloupe } \\
\text { (Le Raizet) }\end{array}$} & Naive & $\begin{array}{c}\text { Pers } \\
\text { SC-pers }\end{array}$ & $\begin{array}{l}38.08 \\
27.88\end{array}$ & $\begin{array}{l}36.75 \\
26.81\end{array}$ & $\begin{array}{l}36.29 \\
24.40\end{array}$ & $\begin{array}{l}39.40 \\
30.28\end{array}$ & $\begin{array}{l}39.60 \\
29.55\end{array}$ \\
\hline & \multirow{3}{*}{ Non-linear } & $S V R$ & 25.69 & 24.28 & 23.09 & 28.08 & 26.83 \\
\hline & & $G P$ & 25.95 & 24.88 & 23.31 & 28.25 & 26.88 \\
\hline & & $N N$ & 25.99 & 24.73 & 23.29 & 28.48 & 26.92 \\
\hline
\end{tabular}




\begin{tabular}{|c|c|c|c|c|c|c|}
\hline Linear & $A R$ & 26.74 & 25.03 & 24.10 & 29.32 & 27.96 \\
\hline Gain in rRMSE & & $+2.19 \%$ & $+2.53 \%$ & $+1.31 \%$ & $+2.20 \%$ & $+2.72 \%$ \\
\hline
\end{tabular}

Table 2. rRMSE (\% ) of hour ahead forecasts for Corsica, Reunion and Guadeloupe (in bold, the best results). The line Gain in rRMSE is the difference between the scaled-persistence (SC-pers) rRMSE and the best annual rRMSE

As shown by Table 2, in all the cases, the naive persistence is the model that gives the worst results. Consequently, this model can be definitively discarded in future assessments. From Table 2, the best annual predictors are: NN for Corsica-Ajaccio (rRMSE of 19.65\%), GP for Reunion-Saint Pierre (rRMSE of 21.07\%) and SVR for Guadeloupe-Le Raizet (rRMSE of 25.69\%). The annual performance varies from site to site. As an example, there is almost $6 \%$ difference between the best predictors of Corsica and Guadeloupe. This discrepancy is certainly due to the cloud formation processes, which are very different in these two islands. Indeed, as shown by the sites analysis made in section 2.4 , the two sites experience different sky conditions during the year.

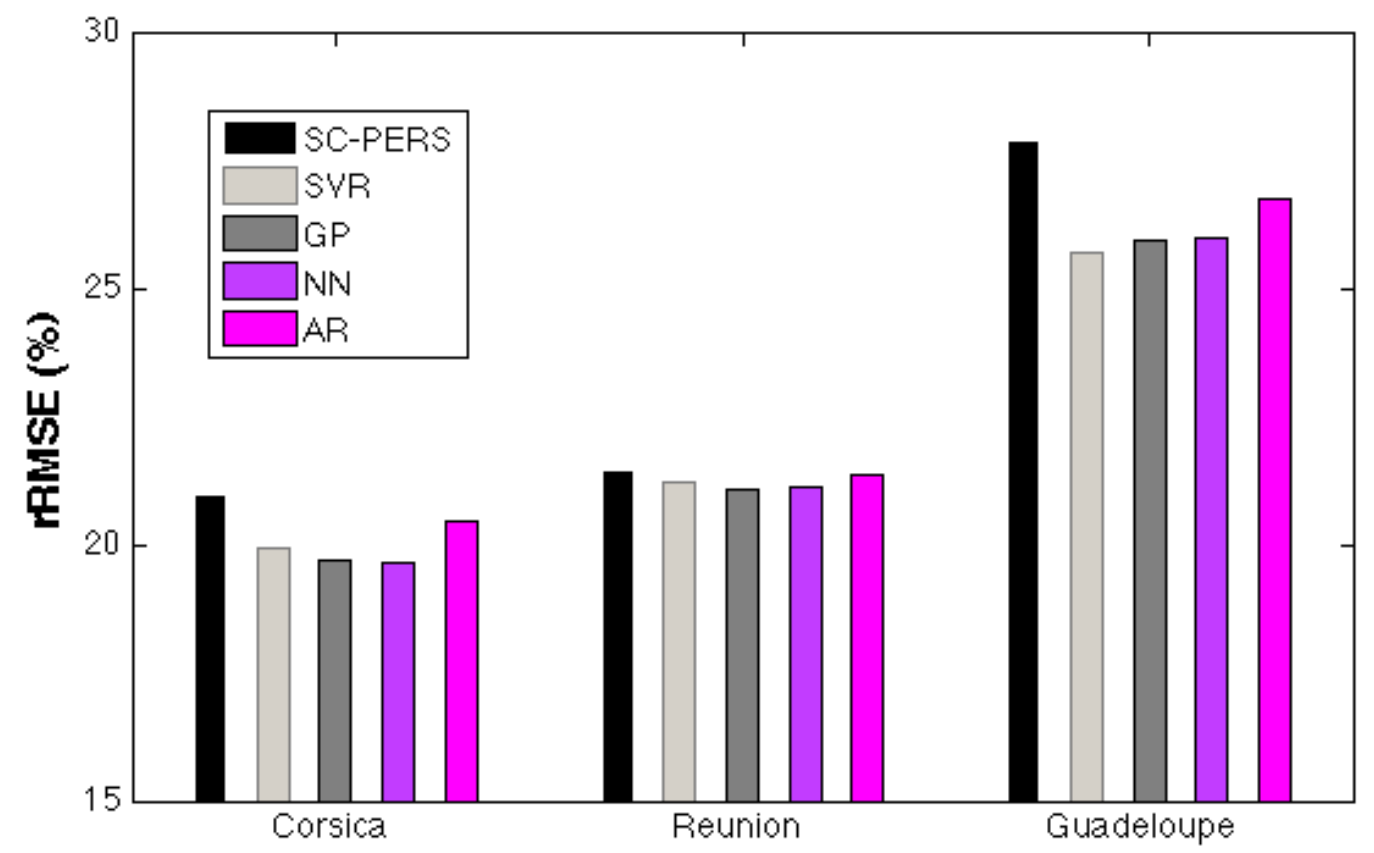

Figure 2. Annual rRMSE (\%) values for the three sites

Actually, if one makes a step further in the analysis of the results, a dichotomy in the results is observed between sites experiencing different sky conditions. More precisely, based on the prior sites analysis, two comments can be made: 
First, for sites like Corsica and Reunion that exhibit stable sky conditions (mainly clear sky conditions), all the methods (except the naive persistence) are practically equivalent (around or less than $1 \%$ rRMSE difference between the new methods and scaled persistence). In the case of La Reunion (which is the site that experiences less variability and longer sequence of clear hours- see Table 1), the annual gain in rRMSE (which is the difference between the rRMSE of the scaled persistence and the best performer) is only of $+0.4 \%$.

Second, for a site that exhibits variable cloud situations like Guadeloupe, the machine learning techniques perform better than the scaled-persistence. The SVR method leads to a gain in rRMSE of $+2.19 \%$

Regarding the seasonal rRMSE, the best result appears in summer in Ajaccio ( $3^{\text {rd }}$ quarter; $r$ RMSE $=15.15 \%$ ) when the occurrence of clear sky is the most important. The worst performance is in Guadeloupe $\left(3^{\text {rd }}\right.$ quarter; rRMSE $=28.08 \%$ ) during the rainy season when the sky cover is highly variable. In the case of La Reunion, for the time period under study, the scaled persistence is the best performer for the $3^{\text {rd }}$ and $4^{\text {th }}$ quarters. This period of the year corresponds to the end of the dry season when the sky is clear very often. As seen, in the case of Le Raizet (Guadeloupe), the performance of the SVR method is quite consistent all along the four quarters.

The analysis of the seasonal results confirms the previous statements we made about the dichotomy of the results that depends on the sky conditions. For instance, when a quarter exhibits a rather good scaled-persistence performance (i.e. rRMSE less than or around 20\%), it is difficult for the nonlinear methods to beat by more than $1 \%-1.5 \%$ the scaled persistence (see for instance $2^{\text {nd }}$ and $3^{\text {rd }}$ quarter of Ajaccio). It may happen also that in some cases the scaled persistence slightly beat the nonlinear methods.

Conversely, when a quarter exhibits rather unstable conditions (scaled persistence with $\mathrm{RMSE}>=24 \%$ ), the nonlinear methods perform better than the scaled persistence $(2 \%-2.5 \%$ better in average). See for instance the 4th quarter of Ajaccio as well as the quarters related to Guadeloupe.

In an attempt to get an overall picture of the ranking of the six predictors for all the three studied sites, we chose to use a simple method of mono criterion analysis based on the rRMSE values (Voyant et al., 2012). More precisely, a total of 21 points per site are distributed among the six methods. The method that exhibits the best annual rRMSE wins 6 points, the second 5 points and so on until the worst that wins only one point. Table 3 lists the overall ranking of the predictors.

\begin{tabular}{ccc}
\hline Types & Points & Ranking \\
\hline GP & 16 & 1 \\
NN & 15 & 2 \\
SVR & 14 & 3 \\
AR & 9 & 4 \\
SC-pers & 6 & 5 \\
Pers & 3 & 6 \\
\hline
\end{tabular}


Table 3. Overall ranking of the different predictors for hour ahead forecasts (monocriterion analysis based on the annual rRMSE value)

The GP model led most of the time to the best results (16 points). Conversely, the persistence model gave the worst results. It is certainly not significant but from Table 3 we can consider that the non-linear models are the more suitable for hour ahead solar forecasting, followed by the linear method and naive estimations. Actually, section 6.2 will confirm this previous statement for forecast horizons ranging from 2 to 6 hours. Based on this survey, the difference between the three best performing predictors i.e. SVR, NN and GP methods is not enough significant to propose a conclusive ranking. With other locations or different period of data, maybe the ranking would be different between SVR, NN and GP. But, globally, these three predictors should be considered equivalent for hour ahead forecasting until new studies will demonstrate the contrary.

In the next section, we make a step further by assessing the accuracy of the different methods for forecasting horizons ranging from 2 to 6 hours.

\subsection{Intra-day solar forecasting}

This section evaluates the accuracy of the different methods for forecast horizon up to 6 hour ahead. Tables 4-6 give (on the one year validation period) the rMBE, rRMSE and rMAE values of the different methods for each forecasting time horizon. Mean GHI is given for each site from which one can infer the absolute values from the relative values.

For forecasting time horizons greater than one hour, Tables 5-6 show that the nonlinear methods perform better than the scaled-persistence and the linear model in terms of rRMSE and rMAE. As shown by Tables 5-6, the gain increases with the forecasting horizon and is more important for the site of Le Raizet (Guadeloupe).

Except the linear AR model, all the methods do rather well in terms of rMBE (see Table 4) and a slight increase of the rMBE is also observed with the forecasting horizon.

\begin{tabular}{|c|c|c|c|c|c|c|c|}
\hline Site & Model & $\begin{array}{l}1 \text { hour } \\
\text { ahead }\end{array}$ & $\begin{array}{l}2 \text { hour } \\
\text { ahead }\end{array}$ & $\begin{array}{l}3 \text { hour } \\
\text { ahead }\end{array}$ & $\begin{array}{l}4 \text { hour } \\
\text { ahead }\end{array}$ & $\begin{array}{l}5 \text { hour } \\
\text { ahead }\end{array}$ & $\begin{array}{l}6 \text { hour } \\
\text { ahead }\end{array}$ \\
\hline \multirow{2}{*}{$\begin{array}{l}\text { Corsica } \\
\text { (Ajaccio) }\end{array}$} & Pers & -0.01 & -0.03 & -0.05 & -0.07 & -0.08 & -0.09 \\
\hline & SC-pers & -0.76 & -1.29 & -1.62 & -1.73 & -1.61 & -1.31 \\
\hline \multirow{2}{*}{$\begin{array}{c}\text { mean } \\
\mathrm{GHI}=428.53 \\
\mathrm{~W} \cdot \mathrm{m}^{-2}\end{array}$} & SVR & 0.20 & 0.43 & 0.56 & 0.31 & 0.97 & 1.57 \\
\hline & GP & -0.11 & -0.61 & -0.85 & -0.97 & -0.74 & -0.87 \\
\hline
\end{tabular}




\begin{tabular}{|c|c|c|c|c|c|c|c|}
\hline & $N N$ & -0.22 & -0.52 & -1.00 & -1.12 & -1.04 & -0.84 \\
\hline & $A R$ & -2.43 & -4.12 & -5.30 & -6.24 & -6.99 & -7.60 \\
\hline \multirow{6}{*}{$\begin{array}{c}\text { Reunion } \\
\text { (Saint-Pierre) } \\
\text { mean } \\
\text { GHI }=535.06 \\
\text { W. } \mathrm{m}^{-2}\end{array}$} & Pers & 0.01 & 0.02 & 0.04 & 0.07 & 0.10 & 0.11 \\
\hline & SC-pers & 0.22 & -0.19 & -1.05 & -2.11 & -3.08 & -3.74 \\
\hline & SVR & -2.75 & -2.61 & -2.65 & -2.70 & -2.45 & -2.39 \\
\hline & $G P$ & -1.84 & -2.80 & -3.62 & -3.77 & -3.81 & -3.59 \\
\hline & $N N$ & -1.73 & -2.77 & -3.50 & -4.22 & -3.57 & -3.43 \\
\hline & $A R$ & -1.73 & -3.43 & -5.14 & -6.60 & -7.61 & -8.28 \\
\hline \multirow{6}{*}{$\begin{array}{l}\text { Guadeloupe } \\
\text { (Le Raizet) }\end{array}$} & Pers & -0.01 & -0.01 & -0.02 & -0.03 & -0.05 & -0.07 \\
\hline & SC-pers & 2.04 & 2.63 & 2.24 & 1.07 & -0.56 & -2.24 \\
\hline & SVR & -1.24 & -1.58 & -2.04 & -2.67 & -2.83 & -2.63 \\
\hline & $G P$ & -0.21 & -1.25 & -2.83 & -3.64 & -3.87 & -4.08 \\
\hline & $N N$ & -0.32 & -1.55 & -2.64 & -3.40 & -3.84 & -3.92 \\
\hline & $A R$ & -0.61 & -2.30 & -4.21 & -6.16 & -8.17 & -10.26 \\
\hline
\end{tabular}

Table 4. rMBE values for the three sites. The corresponding MBE values can be obtained from the mean GHI of each site.

\begin{tabular}{|c|c|c|c|c|c|c|c|}
\hline Site & Model & $\begin{array}{l}1 \text { hour } \\
\text { ahead }\end{array}$ & $\begin{array}{l}2 \text { hour } \\
\text { ahead }\end{array}$ & $\begin{array}{l}3 \text { hour } \\
\text { ahead }\end{array}$ & $\begin{array}{l}4 \text { hour } \\
\text { ahead }\end{array}$ & $\begin{array}{l}5 \text { hour } \\
\text { ahead }\end{array}$ & $\begin{array}{l}6 \text { hour } \\
\text { ahead }\end{array}$ \\
\hline \multirow{6}{*}{$\begin{array}{c}\text { Corsica } \\
\text { (Ajaccio) } \\
\text { mean } \\
\text { GHI=428.53 } \\
\text { W.m. }\end{array}$} & Pers & 31.94 & 52.82 & 68.87 & 80.18 & 86.59 & 88.13 \\
\hline & SC-pers & 21.00 & 28.67 & 33.93 & 37.90 & 40.57 & 42.10 \\
\hline & $S V R$ & 19.92 & 25.63 & 28.63 & 30.57 & 31.68 & 32.41 \\
\hline & $G P$ & 19.71 & 25.34 & 29.40 & 30.76 & 31.97 & 33.79 \\
\hline & $N N$ & 19.65 & 25.49 & 28.69 & 31.06 & 32.10 & 32.76 \\
\hline & $A R$ & 20.43 & 27.19 & 31.61 & 34.92 & 37.20 & 38.76 \\
\hline \multirow{6}{*}{$\begin{array}{c}\text { Reunion } \\
\text { (Saint-Pierre) } \\
\\
\text { mean } \\
\text { GHI }=535.06 \\
\text { W. } \mathrm{m}^{-2}\end{array}$} & & 34.21 & 56.85 & 74.16 & 85.87 & 91.58 & 91.27 \\
\hline & SC-pers & 21.47 & 28.92 & 33.92 & 38.23 & 41.43 & 43.29 \\
\hline & SVR & 21.22 & 26.88 & 29.59 & 31.13 & 31.58 & 31.71 \\
\hline & $G P$ & 21.07 & 26.70 & 29.31 & 30.89 & 31.57 & 31.68 \\
\hline & $N N$ & 21.14 & 26.74 & 29.39 & 31.03 & 31.51 & 31.68 \\
\hline & $A R$ & 21.36 & 27.89 & 31.91 & 35.00 & 37.20 & 38.51 \\
\hline \multirow{6}{*}{$\begin{array}{c}\text { Guadeloupe } \\
\text { (Le Raizet) } \\
\text { mean } \\
\text { GHI }=480.06 \\
\text { W. } \mathrm{m}^{-2}\end{array}$} & Pers & 38.08 & 59.85 & 76.16 & 87.58 & 93.30 & 93.34 \\
\hline & SC-pers & 27.88 & 36.92 & 42.63 & 47.11 & 49.47 & 50.29 \\
\hline & SVR & 25.69 & 31.36 & 33.67 & 34.72 & 35.02 & 35.16 \\
\hline & $G P$ & 25.95 & 31.54 & 33.88 & 34.73 & 35.42 & 35.36 \\
\hline & $N N$ & 25.99 & 31.54 & 33.78 & 34.77 & 35.09 & 35.41 \\
\hline & $A R$ & 26.74 & 33.78 & 37.78 & 40.74 & 42.64 & 43.39 \\
\hline
\end{tabular}


Table 5. rRMSE values for the three sites. The corresponding RMSE values can be obtained from the mean GHI of each site.

\begin{tabular}{|c|c|c|c|c|c|c|c|}
\hline Site & Model & $\begin{array}{l}1 \text { hour } \\
\text { ahead }\end{array}$ & $\begin{array}{l}2 \text { hour } \\
\text { ahead }\end{array}$ & $\begin{array}{l}3 \text { hour } \\
\text { ahead }\end{array}$ & $\begin{array}{l}4 \text { hour } \\
\text { ahead }\end{array}$ & $\begin{array}{l}5 \text { hour } \\
\text { ahead }\end{array}$ & $\begin{array}{l}6 \text { hour } \\
\text { ahead }\end{array}$ \\
\hline \multirow{6}{*}{$\begin{array}{c}\text { Corsica } \\
\text { (Ajaccio) } \\
\text { mean } \\
\text { GHI }=428.53 \\
\text { W. } \text { m }^{-2}\end{array}$} & Pers & 26.15 & 44.39 & 57.31 & 66.94 & 71.12 & 72.03 \\
\hline & SC-pers & 12.50 & 17.92 & 21.73 & 24.62 & 26.42 & 27.60 \\
\hline & SVR & 12.36 & 17.47 & 20.13 & 22.05 & 23.14 & 23.75 \\
\hline & $G P$ & 12.56 & 17.35 & 20.64 & 22.06 & 23.09 & 24.67 \\
\hline & $N N$ & 12.65 & 17.36 & 20.32 & 22.31 & 23.40 & 24.15 \\
\hline & $A R$ & 13.02 & 18.27 & 21.64 & 24.00 & 25.71 & 26.95 \\
\hline \multirow{6}{*}{$\begin{array}{c}\text { Reunion } \\
\text { (Saint-Pierre) } \\
\text { mean } \\
\text { GHI }=535.06 \\
\text { W. } \mathrm{m}^{-2}\end{array}$} & Pers & 28.34 & 48.40 & 63.20 & 73.48 & 78.44 & 77.32 \\
\hline & SC-pers & 13.31 & 18.93 & 22.87 & 25.95 & 27.81 & 28.84 \\
\hline & $S V R$ & 15.91 & 20.54 & 22.73 & 23.91 & 24.05 & 24.15 \\
\hline & $G P$ & 15.49 & 20.35 & 22.61 & 23.77 & 24.10 & 24.01 \\
\hline & $N N$ & 15.61 & 20.34 & 22.60 & 23.90 & 23.96 & 24.04 \\
\hline & $A R$ & 14.57 & 19.94 & 23.03 & 24.89 & 25.86 & 26.40 \\
\hline \multirow{6}{*}{$\begin{array}{c}\text { Guadeloupe } \\
\text { (Le Raizet) } \\
\text { mean } \\
\mathrm{GHI}=480.06 \\
\text { W. } \mathrm{m}^{-2}\end{array}$} & Pers & 31.22 & 50.57 & 64.52 & 73.84 & 78.04 & 78.01 \\
\hline & SC-pers & 19.90 & 26.63 & 30.95 & 34.10 & 35.89 & 36.58 \\
\hline & $S V R$ & 19.35 & 24.02 & 26.18 & 27.07 & 27.38 & 27.29 \\
\hline & $G P$ & 19.69 & 24.25 & 26.47 & 27.23 & 27.66 & 27.57 \\
\hline & $N N$ & 19.71 & 24.28 & 26.38 & 27.21 & 27.51 & 27.62 \\
\hline & $A R$ & 19.59 & 25.00 & 28.16 & 30.25 & 31.60 & 32.12 \\
\hline
\end{tabular}

Table 6. rMAE values for the three sites. The corresponding MAE values can be obtained from the mean GHI of each site.

Table 7 lists the s-skill scores of the different forecasting techniques for each forecasting time horizon. As shown by Table 7, the s-skill scores of the methods increase with the forecasting time horizon. All the models (linear and non linear) exhibit positive scores and therefore perform better than the scaled-persistence. Nonetheless, higher values of s-skill score are obtained with the nonlinear methods. In addition, it appears that sskill scores are more important for a site that exhibits variable cloud situations like Le Raizet (Guadeloupe).

\begin{tabular}{|c|c|cccccc}
\hline Site & Model & $\begin{array}{c}\text { 1 hour } \\
\text { ahead }\end{array}$ & $\begin{array}{c}\text { 2 hour } \\
\text { ahead }\end{array}$ & $\begin{array}{c}\text { 3 hour } \\
\text { ahead }\end{array}$ & $\begin{array}{c}\text { 4 hour } \\
\text { ahead }\end{array}$ & $\begin{array}{c}\text { 5 hour } \\
\text { ahead }\end{array}$ & $\begin{array}{c}6 \text { hour } \\
\text { ahead }\end{array}$ \\
\hline Corsica & SC-pers & 0 & 0 & 0 & 0 & 0 & 0 \\
\cline { 2 - 8 }
\end{tabular}




\begin{tabular}{|c|c|c|c|c|c|c|c|}
\hline \multirow[t]{4}{*}{ (Ajaccio) } & $S V R$ & 5.14 & 10.60 & 15.64 & 19.33 & 21.91 & 23.02 \\
\hline & $G P$ & 6.14 & 11.62 & 13.35 & 18.82 & 21.21 & 19.73 \\
\hline & $N N$ & 6.43 & 11.08 & 15.45 & 18.04 & 20.87 & 22.19 \\
\hline & $A R$ & 2.71 & 5.17 & 6.85 & 7.85 & 8.32 & 7.94 \\
\hline \multirow{5}{*}{$\begin{array}{c}\text { Reunion } \\
\text { (Saint-Pierre) }\end{array}$} & SC-pers & 0 & 0 & 0 & 0 & 0 & 0 \\
\hline & $S V R$ & 1.17 & 7.06 & 12.76 & 18.57 & 23.78 & 26.76 \\
\hline & $G P$ & 1.87 & 7.66 & 13.60 & 19.19 & 23.80 & 26.83 \\
\hline & $N N$ & 1.54 & 7.54 & 13.35 & 18.83 & 23.96 & 26.83 \\
\hline & $A R$ & 0.51 & 3.55 & 5.92 & 8.43 & 10.22 & 11.05 \\
\hline \multirow{5}{*}{$\begin{array}{l}\text { Guadeloupe } \\
\text { (Le Raizet) }\end{array}$} & SC-pers & 0 & 0 & 0 & 0 & 0 & 0 \\
\hline & $S V R$ & 7.86 & 15.05 & 21.02 & 26.31 & 29.22 & 30.08 \\
\hline & $G P$ & 6.92 & 14.57 & 20.53 & 26.28 & 28.40 & 29.69 \\
\hline & $N N$ & 6.78 & 14.58 & 20.78 & 26.19 & 29.08 & 29.60 \\
\hline & $A R$ & 4.09 & 8.51 & 11.40 & 13.54 & 13.80 & 13.73 \\
\hline
\end{tabular}

Table 7. s-skill scores for the three sites

Fig. 3 shows, for the case of Reunion Island (but the results are similar for the other sites) the forecasting accuracy of the different methods for forecasting time horizons up to 6 hours. In addition to the scaled persistence model, Fig. 3 also plots the performance of another reference model. The latter, referred to as climatological mean, is independent of the forecast horizon (Lorenz and Heinemann, 2012). More precisely, this model performs a constant forecast of the clear sky index that corresponds to its mean historical value. In our case, we used the average clear sky index of the year 2012 in order to forecast the clear sky index of the year 2013.

Fig. 3 clearly demonstrates the better performance of the nonlinear methods over the linear AR model and the scaled persistence model when the forecast horizon increases. One may notice also that the performances of the machine learning techniques tend towards that of the climatological mean. This behavior is consistent, as these nonlinear methods tend to asymptotically model the mean of the data. As seen, it is not the case for the linear autoregressive model whose error increases with increasing forecast horizon. It should also be noted that the performance of the three nonlinear methods are practically the same. The choice of the method will depend on the skill and experience of the modeler. Nonetheless, according to our experience and as mentioned above, careful attention must be put in to the building of the NN model. Conversely, again according to our experience 
the construction of the GP and SVR models appear to be part of a more principled framework than the NN methodology.

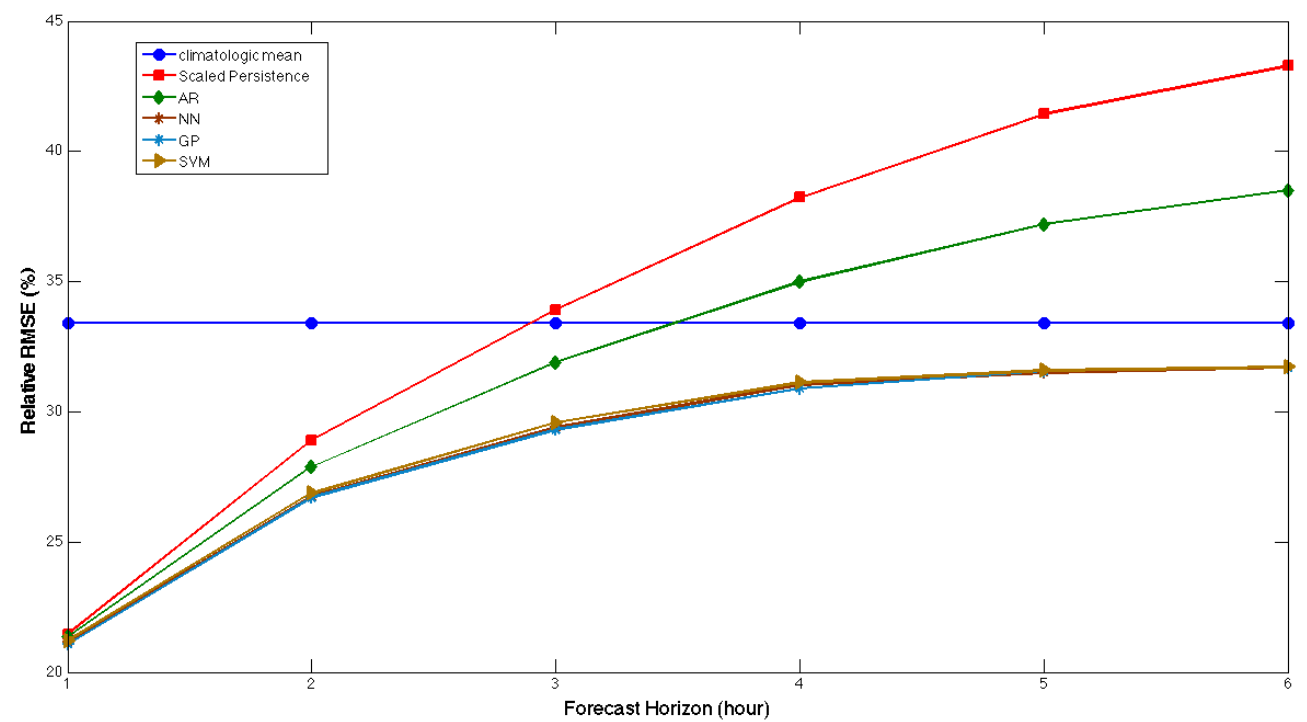

Figure 3. Accuracy of intraday solar forecasting (case of Reunion Island)

\section{Conclusion}

This work proposed a benchmarking of machine learning techniques for intraday solar forecasting. Popular nonlinear techniques such as neural networks, and some rather new methods such as Gaussian Processes and support vector machines were evaluated against simple methods like the autoregressive linear model and reference models like scaled persistence. A choice was made to assess the performances of the different models on historical GHI data, measured on three French islands. This choice was supported by the challenging solar forecasting context, due to the specific insular feature. The main conclusion that can be drawn from this survey is that the machine learning techniques start to outperform their simple counterparts for forecasting horizons greater than one hour. For hour ahead solar forecasting, the picture is less clear and seems to depend on the sky conditions. For stable clear sky conditions (clear skies for instance), the nonlinear methods slightly improve the scaled-persistence. For unstable sky conditions, the discrepancy between the machine learning methods and the simple models is more pronounced with a $2 \%$ rRMSE difference in average. However, this finding must be confirmed by further studies. 
In this study, the building of the forecasting models was made solely by using past GHI measurements. The future operational availability in these islands of exogenous inputs (such as those provided by NWP models or Satellite data) will obviously improve the accuracy of the solar forecasts.

\section{References}

AERONET, 2014. <http://aeronet.gsfc.nasa.gov/>.

Badosa, J., Haeffelin, M., Chepfer, H., 2013. Scales of spatial and temporal variation of solar irradiance on Reunion tropical island. Solar Energy 88, 42-56.

Badescu, V., Gueymard, C. A., Cheval, S., Oprea, C., Baciu, M., Dumitrescu, A., Iacobescu, F., Milos, I., Rada, C., 2013. Accuracy analysis for fifty-four clear-sky solar radiation models using routine hourly global irradiance measurements in Romania. Renewable Energy 55, 85-103.

Bird, R.E. , Hulstrom, R.L., 1981. Simplified the Clear Sky Model for Direct and Diffuse Insolation on Horizontal Surfaces, Technical Report No. SERI/TR-642-761, Golden, CO: Solar Energy Research Institute.

Bishop, C.M., 1995. Neural networks for pattern recognition, Oxford University Press, Oxford.

Calif, R., Schmitt, F.G., Huang, Y., Soubdhan, T., 2013. Intermittency study of high frequency global solar radiation sequences under a tropical climate. Solar Energy 98, 349-365.

Chang, C.C, Lin, C.J, 2011. LIBSVM: A library for support vector machines, <http://www.csie.ntu.edu.tw/ cjlin/libsvm>.

Chatfield, C., 2004. Time series analysis, an introduction, Chapman \& Hall/CRC.

Coimbra, C.F.M, Kleissl, J., Marquez, R., 2013. Overview of Solar-Forecasting Methods and a Metric for Accuracy Evaluation, in: Kleissl, J. (Ed.), Solar Energy Forecasting and Resource Assessment. Elsevier, pp.171-194.

Cros, S., Liandrat, O., Sébastien, N., Schmutz, N., Voyant, C., 2013. Clear Sky Models Assessment for an Operational PV Production Forecasting Solution. In: Proceedings of the 28th European PV Solar Energy Conference, 30 September-4 October, Paris, France.

Czibula, G., Czibula, I.G., Gaceanu, R.D., 2014. A support vector machine model for intelligent selection of data representations. Applied Soft Computing Journal 18, 70-81.

David, M., 2005. Developpement d'un générateur de climat multi-variable, PhD Thesis. Université de La Réunion. 
David, M., Diagne, M., Lauret, P. 2012. Outputs and error indicators for solar forecasting models. In: Proceedings of the World Renewable Energy Forum (WREF), 13-17 May, Denver, Colorado, USA.

David, M., Ramahatana, F.H, Liandrat.,O., 2013. Spatial and temporal variability of PV output in an insular grid: Case of Reunion Island. In: Proceedings of the ISES Solar World Congress, 3-7 November, Cancùn, Mexico.

Diagne, M., David, M., Boland, J., Schmutz, N., Lauret, P., 2014. Post-processing of solar irradiance forecasts from WRF model at Reunion Island. Solar Energy 105, 99-108.

Fonseca Junior., J. G. S., Oozeki, T., Ohtake, H., Shimose, K., Takashima, T., Ogimoto, K., 2013. Analysis of Different Techniques to Set Support Vector Regression to Forecast Insolation in Tsukuba, Japan. Journal of International Council on Electrical Engineering, 3(2), 121-128.

Haurant, P., Muselli, M., Oberti, P., 2009. Solar Atlas Implementation and Multicriteria Context of PV Plant Planning in Corsica Island (France). In: Proceedings of the 24th European Photovoltaic Solar Energy Conference, 21-25 September, Hamburg, Germany.

Hornik, K., Stinchcombe, M., White, H., 1989. Multilayer feedforward networks are universal approximators. Neural Networks 2(5), 359-66.

Hoff, T.E., Perez, R., Kleissl, J., Renné, D., Stein, J., 2012. Reporting of irradiance modeling relative prediction errors. Progress in Photovoltaics: Research and Applications.

Hoff, T.E., Perez, R., 2012. Modeling PV fleet output variability. Solar Energy 86, 2177-2189.

Ineichen, P., 2006. Comparison of eight clear sky broadband models against 16 independent data banks. Solar Energy 80, 468-478.

Inman, R.H., Pedro, H.T.C., Coimbra, C.F.M., 2013. Solar forecasting methods for renewable energy integration. Progress in Energy and Combustion Science 39, 535-576.

Inness, P., Dorling, S., 2012. NWP Models - the Basic Principles, in: Operational Weather Forecasting. John Wiley \& Sons, Ltd, pp. 53-107.

Kostylev, V., Pavlovski, A., 2011. Solar power forecasting performance towards industry standards. In: Proceedings of the 1st International Workshop on the Integration of Solar Power into Power Systems, October 24, Aarhus, Denmark.

Lauret, P., Fock, E., Mara, T.A., 2006. A node pruning algorithm based on the Fourier amplitude sensitivity test method. IEEE Trans Neural Networks 17(2), 273-293. 
Lauret, P., Fock, E., Randrianarivony, R.N., Manicom-Ramsamy, J.F. 2008. Bayesian neural network approach to short time load forecasting. Energy Conversion and Management, 49(5), 1156- 1166.

Lauret, P, David, M., Calogine, D., 2012. Nonlinear Models for Short-time Load Forecasting, Energy Procedia 14, 1404-1409.

Lorenz, E., Heinemann, D., 2012. Prediction of solar irradiance and photovoltaic power, in: Sayigh, A., (Ed.), Comprehensive Renewable Energy. Elsevier, Oxford, pp. 239-292.

MacKay, D.J.C., 1992. A practical Bayesian framework for back-propagation networks. Neural Computation, 4(3), 448-72.

Marquez, R., Coimbra, C.F.M, 2011. Forecasting of global and direct solar irradiance using stochastic learning methods, ground experiments and the NWS database, Solar Energy 8, 746-756.

Maini, A.K., Agrawal, V., 2006. Weather Satellites, in: Satellite Technology: Principles and Applications. John Wiley \& Sons, Chichester, UK, pp. 391-425.

Maxwell, E., Wilcox, S., Rymes, M., 1993. Users manual for seri qc software, assessing the quality of solar radiation data. Report no. NREL-TP-463-5608. 1617 Cole Boulevard, Golden, CO: National Renewable Energy Laboratory.

Mellit, A., Kalogirou, S.A., Hontoria, L., Shaari, S., 2009. Artificial intelligence techniques for sizing photovoltaic systems: A review. Renewable and Sustainable Energy Reviews 13, 406-419.

Müller, K.R., Smola, A.J., Rätsch, G., Schölkopf, B., Kohlmorgen, J., Vapnik, V., 1997. Predicting time series with support vector machines. In: Gerstner, W., Germond, A., M. Hasler, M., Nicoud, J.D (Eds.), Artificial Neural Networks - ICANN 97, Lecture Notes in Computer Science, Springer Berlin, pp 999-1004.

Muselli, M., Notton, G., Canaletti, J.L., Louche, A., 1998. Utilization of meteosat satellite-derived radiation data for integration of autonomous photovoltaic solar energy systems in remote areas. Energy Conversion Management 39, 1-19.

Paoli, C., Voyant, C., Muselli, M., Nivet, M.-L., 2010. Use of Exogenous Data to Improve Artificial Networks Dedicated to Daily Global Radiation Forecasting. In: Proceedings of the 25th European Photovoltaic Solar Energy Conference, 6-10 September, Valencia, Spain.

Parviz, R.K., Nasser, M., Motlagh, M.R.J., 2008. Mutual Information Based Input Variable Selection Algorithm and Wavelet Neural Network for Time Series Prediction. In: Kůrková, V., Neruda, R., Koutník, J. (Eds.), Artificial Neural Networks - ICANN 2008, Lecture Notes in Computer Science. Springer Berlin Heidelberg, pp. 798-807. 
Praene, J.P., David, M., Sinama, F., Morau, D., Marc, O., 2012. Renewable energy: Progressing towards a net zero energy island, the case of Reunion Island. Renewable and Sustainable Energy Reviews 16, 426-442.

Rasmussen, C.E., Williams, C.K.I., 2006. Gaussian Processes for Machine Learning, MIT Press, Cambridge, Massachusetts.

Reno, M.J., Hansen, C.W., Stein, J.S., 2012. Global Horizontal Irradiance Clear Sky Models: Implementation and Analysis, SANDIA report SAND2012-2389.

Smola, A.J., Schölkopf, B., 2004. A tutorial on support vector regression. Statistics and Computing 14, 199-222

Sun, A.Y., Wang, D., Xu, X., 2014. Monthly streamflow forecasting using Gaussian Process Regression. Journal of Hydrology 511, 72-81.

Vapnik, V., 1995. The Nature of Statistical Learning Theory. Springer, New York.

Voyant, C., Muselli, M., Paoli, C., Nivet, M.-L., Poggi, P., Haurant, P., 2009. Predictability of PV power grid performance on insular sites without weather stations: use of artificial neural networks. In: Proceedings of the 24th European Photovoltaic Solar Energy Conference, 21-25 September, Hamburg, Germany.

Voyant, C., Muselli, M., Paoli, C., Nivet, M.-L., 2012. Numerical weather prediction (NWP) and hybrid ARMA/ANN model to predict global radiation. Energy 39, 341-355.

Voyant, C., Paoli, C., Muselli, M., Nivet, M.-L., 2013. Multi-horizon solar radiation forecasting for Mediterranean locations using time series models. Renewable and Sustainable Energy Reviews 28, 44-52.

Voyant, C., Notton, G., Paoli, C., Nivet, M.L, Muselli, M., Dahmani, K., 2014. Numerical weather prediction or stochastic modeling: an objective criterion of choice for the global radiation forecasting. International Journal of Energy Technology and Policy, in press.

Wolff, B., Lorenz, E., Kramer, O., 2013. Statistical Learning for Short-Term Photovoltaic Power Predictions. In: Proceedings of DARE 2013 Workshop on Data Analytics for Renewable Energy Integration, September 23, Prague, Czech Republic.

Ozone, 2014. World Ozone Monitoring Mapping <http://es-ee.tor.ec.gc.ca/e/ozone/ozoneworld.htm>.

Yang, L., Yang, S., Zhang, R., Jin, H., 2014. Sparse least square support vector machine via coupled compressive pruning. Neurocomputing 131, 77-86.

Ye, Q., Ye, N., Yin, T., 2014. Enhanced multi-weight vector projection support vector machine. Pattern Recognition Letters 42, 91-100. 
Zeng, J., Qiao, W., 2013. Short-term solar power prediction using a support vector machine. Renewable Energy 52, 118-127.

\section{Appendix A. Definition of the error metrics}

The following metrics RMSE (Root Mean Square Error), MAE (Mean Absolute Error) and MBE (Mean Bias Error) are used to benchmark the different solar forecasting models:

$$
\begin{aligned}
& R M S E=\sqrt{\frac{1}{N} \sum_{i=1}^{N}\left(G H I_{\text {forecast }, i}-G H I_{\text {measured }, i}\right)^{2}} \\
& M A E=\frac{1}{N} \sum_{i=1}^{N}\left|G H I_{\text {forecast }, i_{i}}-G H I_{\text {measured }, i}\right| \\
& M B E=\frac{1}{N} \sum_{i=1}^{N}\left(G H I_{\text {forecast }, i}-G H I_{\text {measured }, i}\right)
\end{aligned}
$$

where $N$ is the number of points in the dataset for the considered period. Relative values of these metrics (rRMSE, rMAE and rMBE) are obtained by normalization to the mean ground measured irradiance of the considered period.

\section{List of captions}

Table 1. Sites characteristics, input parameters for the BIRD model and performance of the Bird model

Table 2. rRMSE (\%) of hour ahead forecasts for Corsica, Reunion and Guadeloupe (in bold, the best results). The line Gain in rRMSE is the difference between the scaled-persistence (SC-pers) rRMSE and the best annual rRMSE

Table 3. Overall ranking of the different predictors for hour ahead forecasts (monocriterion analysis based on the annual rRMSE value)

Table 4. rMBE values (in \%) for the three sites. The corresponding MBE values can be obtained from the mean GHI of each site.

Table 5. rRMSE values (in \%) for the three sites. The corresponding RMSE values can be obtained from the mean GHI of each site.

Table 6. rMAE values (in \%) for the three sites. The corresponding MAE values can be obtained from the mean GHI of each site. 
Table 7. s-skill scores for the three sites

Figure 1. Clear sky index distribution for the three sites.

Figure 2. Annual rRMSE (\%) values for the three sites

Figure 3. Accuracy of intraday solar forecasting (case of Reunion Island) 